\title{
Estudio identitario de la revolución evolutiva en la obra de Manuel González Prada
}

\section{The Study of Identity Related with Evolutionary Revolution in the Writings by Manuel González Prada}

\author{
Santiago Sevilla-Vallejo \\ Universidad de Salamanca, Castilla y León, España \\ Contacto: santiagosevilla@usal.es \\ https://orcid.org/0000-0002-9017-4949
}

\section{RESUMEN}

La formación de la identidad de los colectivos es esencial para la comprensión de su historia. Manuel González Prada es uno de los autores más importantes en la definición de la identidad peruana. Denunció la identidad compuesta de prejuicios, miedos atávicos y sometimiento a la autoridad heredada del dominio español y trabajó para construir una identidad social basada en la ciencia, la rebeldía y la libertad. En este trabajo, se estudia la construcción identitaria que hace el autor desde el modelo narrativo de Paul Ricoeur y del cambio de la lógica cultural definida por Jean Pierre Olivier de Sardan. Para ello, se analizan los siguientes textos: Páginas libres (1894), Horas de lucha (1908), Bajo el oprobio (1933) y Anarquía (1946). En estas obras, Manuel González Prada critica la identidad de dominio que prevalecía en la sociedad peruana, por la que un grupo se impone a otro grupo, el cual responde con humildad y resignación. Por ello, insta a un cambio de la identidad colectiva, que se caracterice por el sentido crítico, es decir, promueve una actitud social de orgullo y rebeldía frente a los abusos del poder. De este modo, la revolución propuesta por Manuel González Prada llevaría a un cambio en la ipseidad ricoeuriana y a la ruptura de una lógica cultural de la corrupción.

Palabras clave: Manuel González Prada; Identidad; Lógica cultural; Libertad; Revolución

\section{ABSTRACT}

The formation of the identity of collectives is essential for the understanding of their history. Manuel González Prada is one of the most important authors in the definition of Peruvian identity. He denounced the identity composed of prejudices, atavistic fears and submission to the authority inherited from Spanish rule and worked to build a social identity based on science, rebellion and freedom. In this paper, we study the construction of identity made by the author from the narrative model of Paul Ricoeur and the change of the cultural logic defined by Jean Pierre Olivier de Sardan. For this purpose, the following texts are analyzed: Páginas libres (1894), Horas de lucha (1908), Bajo el oprobio (1933) and Anarquía (1946). In these works, Manuel González Prada criticizes the identity of domination that prevailed in Peruvian society, whereby one group imposes itself on another group, which responds with humility and resignation. Therefore, he urges a change in the collective identity, characterized by a critical sense, that is, he promotes a social attitude of pride and rebellion against the abuses of power. Thus, the revolution proposed by Manuel González Prada would lead to a change in the Ricœurian ipseidad and to the rupture of a cultural logic of corruption.

Keywords: Manuel González Prada; Identity; Cultural Logic; Freedom; Revolution 
[...] piensa que el futuro para los españoles está donde lo encontraron en el pasado, en América, aunque ahora les toque otro papel, el que quizás siempre tendrían que haber tenido, el de humildes inmigrantes.

Yanet Acosta, Matar al padre

\section{Algunas nociones sobre la identidad nacional}

La construcción de una identidad nacional como un conjunto de rasgos de formas de sentir, pensar y actuar en los que una población puede verse reflejada es un proceso largo y complejo. Tal como establece la teoría ricoeuriana, la identidad es fruto del discurso (Roca, 2003, p. 14) y, en el caso de los países de Hispanoamérica, el discurso identitario es especialmente complicado debido a un conjunto de circunstancias históricas. Manuel González Prada se ocupa de la cuestión en estos países en conjunto y específicamente en Perú. Este autor nació algunos años después de la guerra de Independencia, que dejó al país dividido (Martínez, 2015, p. 67) y vivió en su niñez la guerra civil que ahondó en esa división. Asimismo, tras la derrota en la guerra del Pacífico, llevó a cabo una actividad política y cultural que perseguía tanto luchar contra la influencia española como por la unión interior del país a través de un nuevo sentido de identidad nacional (Tauzin-Castellanos, 2005, p. 2).

Tanto los individuos como los colectivos necesitan definir su propia forma de sentir, pensar y actuar para conformar su naturaleza, así como las diferencias que tienen en esos aspectos con otros individuos o colectivos; todo ello dará lugar a la relación con estos y con el medio en el que viven. Cada sujeto tiene de forma inseparable su identidad individual y su identidad como parte de un colectivo o, en palabras de Pepe Carvalho, cada uno de nosotros es también una nación, "[u]n sujeto colectivo" (en Vázquez, 2004, p. 22). Antes de seguir avanzando, es conveniente dar una breve indicación sobre cómo se construye el sujeto. De acuerdo con la teoría de Paul Ricoeur, la identidad del sujeto se forma siempre en relación con otras personas:

[...] el "yo" se convierte en el primero de los indicadores; señala a aquel que se designa a sí mismo en toda enunciación que contenga la palabra "yo", llevando tras él el "tú" del interlocutor. Los demás indicadores [...] se reagrupan en torno al sujeto de la enunciación. (1996, pp. 24-25)

Podemos pensar en el sujeto como una persona o en el sujeto como colectivo con unas características determinadas. Cualquiera de estos sujetos posee una mismidad, que se refiere a los rasgos que le definen como sujeto individual, y una alteridad, la relación que establece con otros sujetos individuales o sujetos colectivos (Sevilla-Vallejo, 2019, pp. 3-4). La construcción de la identidad es un tema inexcusable porque

[...] no es ningún tipo de esencia dada a priori, sino que se acerca más a un simulacro o una ficción lingüística y cultural (construida sobre todo a partir de estrategias narrativas y que, por tanto, no tiene ningún tipo de consistencia ontológica). (Roca, 2003, p. 14)

La manera con la que un pueblo cuenta su historia define la memoria que queda de ella, la imagen que tienen sus miembros de sí mismos en un momento dado y las expectativas de futuro que ellos albergan. Como señala Ascensión Martínez, los pueblos configuran un programa nacional que establece un sentido de unidad y una dirección de sus acciones (1994, p. 335). En este trabajo, queremos acercarnos al proyecto de transformación de la identidad nacional que Manuel González Prada trató de construir. Para ello, vamos a analizar fragmentos de Páginas libres, Horas de lucha, Bajo el oprobio y Anarquía. Somos conscientes de que es un estudio parcial para una cuestión de gran complejidad, por lo que solo se pretende una aproximación a algunos de los razonamientos con los que el autor buscó un cambio social que sigue siendo de actualidad en Perú y en otros muchos países de Hispanoamérica. Este estudio parte de un marco teórico compuesto por el modelo narrativo de Paul Ricoeur y el cambio de la lógica cultural definida por Jean Pierre Olivier de Sardan. Ello ha sido previamente empleado para estudiar Los comentarios reales del Inca Garcilaso de la Vega (Sevilla-Vallejo, 2020). 


\section{Pasos hacia una independencia cultural}

Pretendemos acercarnos a Manuel González Prada como un autor que ofrece claves vigentes no solo para Perú, sino también para Hispanoamérica En tal sentido, García Márquez escribió en un artículo que la llegada de los españoles dio lugar a una nueva narrativa del continente, la cual trataba de explicar la magnitud del cambio histórico que supuso un encuentro que desbordó y sigue desbordando los discursos que se han construido sobre el Nuevo Mundo (2004, p. 284). En el caso que nos ocupa, Ortega ha estudiado la forma con que los distintos narradores peruanos han ido modelando la propia realidad de su país a lo largo de la historia (1988, p. 137). De modo que, desde ese momento en adelante, la identidad de lo que después serían los países hispanoamericanos ha resultado muy complicada. La convivencia de los nativos, de los negros que fueron traídos como esclavos y de los europeos que acabarían por convertirse en los criollos dio lugar a una segregación en razas que se relaciona con una difícil convivencia como colectivo (García Márquez, 2004, p. 285). La independencia de los territorios hispanoamericanos pudo servir para acabar con esta segregación en Hispanoamérica, pero en lugar de ello se llegó a una realidad social incierta que puede ser terreno de cultivo para que los autores sean creativos a la hora de proponer rasgos de identidad de los colectivos a los que pertenecen (García Márquez, 2004, p. 286). Asimismo, el Nobel colombiano señala el problema de una

[...] educación conformista y represiva [que] parece concebida para que los niños se adapten por la fuerza a un país que no fue pensado para ellos, en lugar de poner el país al alcance de ellos para que lo transformen y engrandezcan. (García Márquez, 2004, p. 288).

Esto va mucho más allá del ámbito educativo, porque el modelo que genera de dominio-pasividad se extiende al conjunto de la cultura. El proyecto de escritura de Manuel González Prada responde a ambos aspectos. En sus ensayos aborda el problema de la identidad del pueblo peruano, el cual está muy relacionado con la pasividad a la que este es inducido.

Manuel González Prada participó de la inquie- tud de descubrir lo verdaderamente peruano. Señaló con vehemencia los abusos cometidos por la conquista española y la división social que dejó la Independencia (Martínez, 2015, p. 67), y denunció también cómo perduró una mentalidad que impedía el progreso del país y la obtención de una verdadera identidad nacional. Abordamos este texto con la intención de indagar en el trabajo intelectual de Manuel González Prada para provocar un cambio social que diera lugar a una verdadera liberación de su país. Tal como ha estudiado Ortega, este autor rechaza la tradición en favor de la necesaria reforma que debía experimentar el país (1988, p. 37). Para mantener el rigor científico, vamos a analizar textualmente citas del autor y nos apoyaremos en un corpus de estudios previos. Somos conscientes de que todo trabajo que se refiera a la identidad de un colectivo histórico es justamente discutible, pero es también necesario tratar de comprender el sentido social de la obra de Manuel González Prada. Este autor tenía una voluntad universalista que hace que muchas de sus afirmaciones, además de referirse a Perú, puedan servir a otros países de habla hispana e incluso contener un valor antropológico (Ward, 2004, p. 175).

Manuel González Prada fue uno de esos autores para los que la cultura respondía y dialogaba con cuestiones sociales. En este breve trabajo no vamos a tratar de recoger la trayectoria del autor de forma sistemática, más bien nos concentraremos en el análisis de las obras mencionadas. Remitimos al lector interesado en este tema a los trabajos de Isabelle Tauzin-Castellanos (1998; 2004; 2005). Podemos comenzar con testimonios de autores contemporáneos y del propio González Prada que muestran su proyecto de construcción de la identidad nacional peruana. En un primer momento, se identifica con el carácter crítico del Club Literario. Eugenio Larraburre y Unánue, uno de sus presidentes, define el motivo que une a los intelectuales después de la guerra con Chile: "Encontraremos todos el gran secreto de cicatrizar las heridas aún abiertas [...] y de vigorizar el organismo nacional, gastado tristemente por las estériles luchas en que se ha consumido nuestra vida interior" (Tauzin-Castellanos, 1998, p. 514). El Club Literario percibió que el proyecto cultural del país había adquirido características de violencia y falta de desarrollo científico y artístico, por lo que era preciso un renacer de la independencia y del progreso. Se planteó que "[1]a independencia cultural respecto a España y la bús- 
queda de la verdad habían de ser el nuevo credo de la élite intelectual; así los escritores serían los adalides de una segunda Independencia" (Tauzin-Castellanos, 1998, p. 516). Esta es una renovación de la vitalidad de la cultura de Perú que sigue siendo un reto por el que luchar. Sin embargo, González Prada y otros intelectuales percibieron entonces una falta de verdadera actividad del Club Literario, por lo que decidieron fundar el Círculo Literario para tener una mayor iniciativa. González Prada fue nombrado su presidente y la Revista Social lo describe como: "amante de la juventud, liberal [...], peruano de corazón, no quiere que la literatura de su patria sea el reflejo de la literatura peninsular, sin vida, sin inspiración propia" (Tauzin-Castellanos, 1998, p. 519).

La guerra del Pacífico fue uno de los grandes detonantes de la crisis material y espiritual de Perú a finales del siglo XIX y comienzos del siglo XX. La impotencia militar frente a la ocupación chilena cargó de sentido social a la literatura:

¿Cómo interpretar esta etapa de la inmediata posguerra? Fue una transmutación del patriotismo guerrero en literatura nacional. Ante la imposibilidad de recuperar las provincias perdidas, los escritores más jóvenes se esmeraron en crear una literatura propiamente peruana; fueron los abanderados de una reconquista interior. (Tauzin-Castellanos, 1998, p. 526) con que estos se muestran salvajes y se asemejan a otros líderes que representan el salvajismo por antonomasia, como Behanzin o Suluque. Por ello, se lamenta de que "a los noventa años de independencia, no se concibe y mueve a náuseas: nacemos libres y nos convenimos a vivir esclavos" (1933, p. 166). Estos gobernantes representan el gobierno despótico y la ambición absurda y tiránica.

Asimismo, pese a la defensa que hace de la igualdad entre los seres humanos, su pensamiento se vio influido por el discurso colonialista que asociaba sumisión, esclavitud y negritud, y que defendía esta discriminación con supuestos criterios científicos (Velázquez, 2005, p. 250). Entonces, todo aquello que mantiene alguna relación con el África negra simboliza para él esa humanidad que no ha salido del salvajismo, porque se somete a gobernantes tiranos mientras estos son fuertes y acaban con ellos cuando caen en desgracia y los sustituyen por nuevos tiranos. "Los pueblos proceden con sus mandatarios y sus grandes hombres como el negro de África se maneja con su fetiche: hoy le adora, mañana le golpea y hasta le destroza" (González Prada, 1933, p. 68). Según Salvattecci, el escritor reclama la igualdad de los hombres, aunque no es capaz de liberarse de los prejuicios que le provocan ciertos grupos como las personas negras de África (en Bretoneche, 2008, p. 106). Dividía a la humanidad en dos clases de pueblos: los civilizados, que disponían de "libertad, educación, conocimiento,

\section{La revolución pretendida por González Prada exige una nueva narración en el que redefina la mismidad del sujeto como alguien con iniciativa y que, por lo tanto, también debe respetar la iniciativa de los otros, que constituyen la alteridad.}

Los autores buscaron una regeneración del país (Larson, 2004, pp. 164-165), que, según percibió González Prada, se vio paralizada por la división y la violencia. "Entre los orangutanes pueden reinar el estacazo y el mordisco, entre los salvajes se concibe la trampa y la flecha; entre los hombres civilizados no cabe más imperio que el de la razón y la justicia" (1933, p. 8). En el pensamiento de González Prada reside una idea de la evolución de las sociedades. El desarrollo de la cultura debería conseguir una sociedad cada vez mejor. En tal sentido, sería esperable que, conforme una sociedad se va haciendo más longeva, esta tuviera gobernantes más formados, justos y beneficiosos. Sin embargo, González Prada se encuentra ciencia, rebeldía y altos valores ético-morales", que se correspondían con occidente (especialmente Europa y Norteamérica); y los salvajes, que no habían alcanzado estos logros y que localizó en Asia, África y Latinoamérica (Bretoneche, 2008, p. 110). De este modo, unos países simbolizan la libertad y el progreso y otros la dominación y el atraso.

Tras la guerra con Chile, los intelectuales soñaron con una reconstrucción material y moral que pronto quedó defraudada por la falta de un verdadero proyecto nacional. González Prada percibió que Perú no recuperaría su autonomía económica ni política debido a la corrupción de sus líderes y a la mansedumbre con la que la población acepta los abusos. El 
problema para cambiar la sociedad es que aquellos que tienen las herramientas para hacerlo han perdido el interés por el bien común y, en caso de encontrarlo, "[s]ólo el limpio de infidencias y prevaricaciones ofrece garantías de operar una transformación social o un simple saneamiento político" (González Prada, 1933, p. 23). Por otro lado, los líderes corruptos prosperan ante la falta de reacción social a sus atropellos:

El buen ciudadano tiene oídos para oír y ojos para ver, mas no tiene boca para hablar. $i$ Acertaría Zola al decir que el peor canalla era el hombre honrado? No cabe duda [de] que en la pusilanimidad de las gentes honradas estriba la fuerza de los pícaros; los buenos merecerían llamarse encubridores y hasta cómplices de los malos. (González Prada, 1933, p. 25)

Trata de despertar las conciencias de los ciudadanos para que reclamen que sus gobernantes trabajen por el bien común. Este es un tema muy interesante por cuanto sigue sin resolverse en Perú y en otros muchos países de habla hispana.

\section{Del adormecido estómago al inquieto corazón}

El principal problema del salvajismo que combate González Prada es que establece un horizonte de expectativas muy limitado. Tal como ha estudiado Taylor, existe una compleja relación entre los ideales sociales que se espera alcanzar y la afirmación de la vida ordinaria o de las necesidades más básicas (1992). En cualquier caso, González Prada señala que en su país concurre un modelo social por el que el éxito no está puesto en la inteligencia ni en producir bienes para la sociedad ni en la belleza, sino en ejercer el poder, de modo que la sociedad se divide entre aquellos que dominan sin ningún fin y aquellos que son dominados:

Hay personajes de cabeza y pecho vacíos, que son un sable y un sombrero de picos, un frac y una medalla, o una capa pluvial y una mitra; y sin embargo, todos les hacen genuflexiones, les rinden homenaje y hasta les elevan a la condición de fetiches. (González Prada, 1933, p. 29)

El autor hace énfasis en la vanagloria absurda de los militares: "¡Cómo arrastran por las aceras los sables! Al verles tan llenos de sí, tan orondos, tan cre- cidos, tan soberbios, cualquiera se imaginaría que regresan de haber conquistado Chile" (González Prada, 1933, p. 46). Estos militares no tienen verdaderos motivos de orgullo, pero engrandecen sus acciones como si fueran una versión adulterada de las batallas quijotescas. Así creen salir victoriosos de descomunales enfrentamientos con gigantes, cuando en realidad no hacen sino pelear con cueros de vino tinto (González Prada, 1933, p. 47).

Son muchas las sociedades donde el modelo social de comportamiento no se dirige al bien común y al progreso, sino a la búsqueda del control sobre los demás. En esas sociedades se establece una lógica cultural por la que se admira a aquel que adquiere preeminencia sobre los demás, más que por sus méritos por su misma influencia. Este modelo social da forma a una identidad colectiva del dominio. En tal sentido, González Prada dice que Billinghurst "no busca hombres de ideas propias, enérgicos, aptos para colaborar en una reforma gubernativa: elige individuos sin voluntad, maleables, resignados al papel de secretarios o firmantes en barbecho" (1933, p. 60). Lucha contra una identidad nacional de la jerarquía hueca, de adorados y adoradores del poder por el poder. La mayor dificultad es que esa identidad da lugar a los "intrigantes de oficio" (González Prada, 1933, p. 70), que dedican sus energías a tramar la forma de obtener el poder para sus propios fines y no para resolver un conflicto social: "generalmente, un prefecto, un diputado y un ministro se hallan más cerca de Ginesillo que de Cincinato" (González Prada, 1933, pp. 71-72).

En 1914, nuestro autor publicó el artículo $E l C a^{-}$ poralismo, que hizo que el gobierno del coronel Benavides cerrara el diario La Protesta de Lima. En él denunciaba una psicología colectiva que tiene un fuerte arraigo en el mundo hispánico. Parece que

[...] hoy se repite como habiendo encontrado al fin la panacea de todos nuestros males: "Aquí se necesita un buen tirano". Esta frase, obligada en boca de muchos infelices, denuncia un estado de alma, equivale al "iVivan las cadenas!" lanzado en España por los súbditos de Fernando VII. (González Prada, 1933, p. 78)

Se produce una identidad colectiva relativa a la sumisión. La población demanda unos líderes fuertes, aunque sea a costa de la libertad ciudadana. 
Las tiranías, por mucho que pregonen la honradez y la economía, derrochan el oro en favoritos y pretorianos; las tiranías funcionan en provecho de una clase, de una casta y a veces de una familia, con detrimento de la gran masa popular. (González Prada, 1933, p. 79)

Aunque el contexto histórico que vivimos hoy en día es muy diferente y en teoría ni en Perú ni en otros países hispanos tenemos tiranos, puede que se mantenga la mentalidad encubierta de que el poder es la forma de poseer los bienes de un determinado Estado.

Uno se podría preguntar si en los países donde hay claras muestras de corrupción no hay voces críticas que denuncien los abusos del poder. El asunto es complejo porque, en los términos de Jean Pierre Olivier de Sardan, la corrupción que se mantiene en el tiempo establece una lógica cultural de la fractura social (Tavits, 2005, p. 5); es decir, la falta de apoyo mutuo se convierte en el modo común de comportamiento. De este modo, el colectivo incorpora en la narrativa de su identidad la falta de solidaridad y, por lo tanto, se repite de generación en generación la protección de los intereses particulares y así se perpetúa la diferencia entre una minoría que dispone de la mayoría de los medios (aunque no sean siempre las mismas personas quienes formen esa minoría) y el resto, que tiene mucho menos. Esta situación se estabilizará en la medida que la población se conforme y piense poco al respecto de la injusticia:

[...] las tiranías, en fin, persiguen el aflojamiento de las voluntades y la emasculación de los cerebros, ahogan toda manifestación libre de la pluma o de la palabra y quieren imponer un largo silencio de tumbas, interrumpido únicamente por el arrastrar del sable. (González Prada, 1933, p. 80)

Los intelectuales son los llamados a despertar la conciencia de la población, pero el problema es que no tienen una verdadera formación crítica, sino una mezcolanza de influencias e ideas mal elaboradas: "Tienen por ciencia un revoltijo de adaptaciones francesas, préstamos italianos y lucubraciones propias, algo así como un bebistrajo compuesto de champagne sofisticado, lacrima cristi inferior y guarapo nacional" (González Prada, 1933, pp. 98-99).
Asimismo, existe una fuerte presión social para que incluso los intelectuales renuncien a su sentido crítico (González Prada, 1976, p. 223).

González Prada sostiene la tesis de que hay una lógica cultural por la que la atención se centra en satisfacer las necesidades y quedan en segundo lugar el valor y la razón:

Nuestra fealdad y pequeñez nos vienen de conceder al estómago la supremacía sobre el corazón. Aquí no hay más que atiborrar a las gentes para verlas tranquilas, felices y mudas: Rocinantes de mansedumbre evangélica, los peruanos aguantan silla, freno y espuelas, con tal de tener asegurada la ración de pasto. (1933, p. 110)

Se impone, asimismo, el conformismo social que hace que la sociedad quede inmóvil.

Hay recién venidos al mundo que no han abierto los ojos y ya parecen la reducción de un magistrado, de un alcalde municipal, de un rentista, de un senador, de un canónigo y hasta de un obispo: infunden respeto y llevan aire de exigirnos el monseñor. (1933, p. 113)

En este contexto, si algún joven quiere tener una actitud crítica con los valores heredados, su madre le detiene diciéndole "[t]onto, come y calla" (1933, p. 115). El escritor alegoriza aquí cómo el dar satisfacción al estómago es la motivación que predomina sobre cualquier otra, sin que los ciudadanos tengan más inquietudes ni alberguen en sus corazones verdaderas pasiones.

Por último, el intelectual expone un contraste entre aquellos países que están gobernados por el bien común y aquellos donde el poder se engrandece a sí mismo en forma de tiranía. "En naciones bien organizadas y sometidas al régimen representativo, la acción del mandatario queda sumamente restringida por la vigilancia y el control del parlamento" (González Prada, 1933, pp. 110-111). De acuerdo con esto, las funciones del gobierno debieran restringirse a velar por el orden y el bien. Sin embargo, la sociedad peruana otorgaba un gran poder al gobierno, incluso hasta la posibilidad de reprimir la libertad de expresión. Los políticos eliminaban la oposición de la prensa mediante "la confiscación del periódico, la cárcel, 
la deportación y a veces la acometida brutal de los esbirros" (1933, p. 121). Así, erradicaban a aquellos que iban en contra de sus intereses, como ocurrió también en el caso español que recuerda el autor: "A la hora de la muerte, el general español Narváez declaraba a su confesor no tener enemigos que perdonar: les había fusilado a todos" (1933, p. 124).

\section{Las revoluciones maleadas y la revolución evolutiva}

Thomas Ward muestra cómo González Prada recibe la teoría evolucionista y define una visión del progreso de las sociedades (2001, pp. 26-27) que le lleva a defender una revolución evolutiva (2001, p. 134). La revolución es una forma rápida de la necesaria evolución de una sociedad. El problema de las revoluciones que se produjeron en Perú es que

[...] casi todas se redujeron a pronunciamientos o cuartelazos. Riñas de lacayos para cambiar de señor y librea. Toda buena revolución fué maleada por sus mismos iniciadores, todo restaurador de las libertades públicas terminó por desaforado enemigo de la Constitución y las leyes. (González Prada, 1933, p. 134)

Nuestro autor observa que las revoluciones de los países hispanoamericanos no han perseguido ideales, sino que han aumentado los problemas y la violencia:

Condenamos las revoluciones nacionales porque nos empobrecen, nos deshonran, nos desangran y nos salvajizan. Si en las épocas normales no hay más garantía que la voluntad del sátrapa guarecido en Palacio, durante la guerra civil rige la ley de Lynch aplicada por los malvados a las gentes honradas. (González Prada, 1933, p. 149)

Ello se debe a que esas revoluciones sirven a los intereses particulares de quienes las ponen en marcha:

¿Cómo lograr algo bueno si los culpables mismos encauzan las revoluciones? Cuando no las inician, las fomentan; y cuando no las fomentan, las aclaman en la hora del triunfo para disfrutar los beneficios, sustituyéndose a los ingenuos que de buena fe se arrojaron a luchar por la Constitución y las leyes. (González Prada, 1933, p. 150)
En este sentido, encuentra un contraste con "la Revolución francesa y la Comuna de París, [donde] los injustamente llamados fieras o bandidos, combatieron por una idea y no cayeron con los bolsillos repletos de oro" (1933, p. 153). Asimismo, señala que en Perú no ha habido una verdadera división de poderes: "Sigue el mismo régimen consistente en un poder único - el Ejecutivo - con dos dependencias igualmente serviles - el Parlamento y el Poder Judicial —" (1933, p. 151). En resumen, indica que "[n]uestras guerras civiles resultan malas, no por carecer de razón, sino porque las hacen o las aprovechan los malos" (1933, pp. 150-151).

Una de las ideas centrales de nuestro autor es que la Independencia fue una oportunidad de que los ciudadanos adquirieran libertad para desarrollarse, pero, en lugar de ello, llevó a la fragmentación y la oposición. "El largo y sinuoso camino hacia la Independencia pasó factura a una sociedad que se fracturó y polarizó en un proceso en el que conveniencias y convicciones no siempre fueron factores claramente delimitados" (Martínez, 2015, p. 67). Conviven en Perú identidades heterogéneas que, de acuerdo con el autor, debilitan al país (Ward, 2004, p. 162). Se da una dicotomía entre el yo y el otro (Albizúrez, 2016, p. 177) en la que podemos observar distintas divisiones. Parafraseando la teoría de Paul Ricoeur, la dicotomía más importante en términos de la dimensión de la separación es aquella en la que el yo o mismidad, la instancia desde la que se narra la historia, está compuesta por los criollos; frente al otro o alteridad, que es la instancia que es narrada, que se refiere a los indios, a los que se ve claramente inferiores. Tal como señala José Antonio Mazzotti, los discursos sobre los indios "se basan en tópicos y focalización que se mantienen durante el periodo republicano" (en Albizúrez, 2016, p. 178) y Nuestros indios de González Prada viene a terminar con esa continuidad ideológica (Albizúrez, 2016, p. 178) rechazando las teorías naturales de las jerarquías (Ward, 2003). Los indios no tienen ni una personalidad ni unas capacidades diferentes de las de aquellos cuyos orígenes están en Europa, sino que participan del clima social en el que viven (González Prada, 1976, p. 341), por lo que el autor pide para ellos lo mismo que para cualquier otra persona: no humildad y resignación, sino orgullo y rebeldía (González Prada, 1976, p. 343). 
Según el pensamiento de nuestro autor, las revoluciones se malean porque la población ha construido su identidad en torno al dominio, en el que las relaciones sociales se establecen entre dominadores y dominados. Ni unos ni otros pueden funcionar desde la libertad. Por este motivo, González Prada recoge la conciencia nacional en los siguientes términos: "La independencia nos abruma, como una montaña de plomo. Se diría que lamentamos la esclavitud perdida, como pájaros que, lanzados al aire por un descuido del amo, regresan a revolotear y piar en derredor de la jaula" (1976, p. 106). Se adormece la inquietud por todo lo que no sea esa jaula y así la población se vuelve contraria al progreso: "Si persona extraña viene a ofrecernos luz o a querer inocularnos el fermento de la vida moderna, nos sublevamos en masa, nos creemos ofendidos en el orgullo nacional" (1976, p. 52). El escritor considera que hay otros países que han alcanzado un progreso superior al que tiene su país: "[e]s que de nosotros a las naciones europeas hay separación de épocas geológicas: no producimos al hombre social y revolucionario sino al gorila politicante, pretoriano y montonero" (1933, p. 154). En otros países - seguramente idealizados - que constituyen la alteridad, se fomenta una lógica cultural de la conciencia del bien común y del progreso, mientras que González Prada piensa que en su país se forma un falso espíritu político que defiende el poder y que azuza la confrontación.

González Prada tiene puestas sus esperanzas en los intelectuales como iluminadores de la sociedad, a la que deben ayudar a erradicar los prejuicios tradicionales, los miedos atávicos y la imposición de las autoridades sobre el propio pensamiento (1976, p. 227). El problema es que, para que puedan acometer esta tarea, deben cargar sus mensajes de contenido y eliminar toda retórica hueca: "el diagnóstico de la literatura se resume en una línea: congestión de palabras, anemia de ideas" (1976, p. 103). Cuando hayan hecho esto, serán capaces de "contrarrestar el influjo del mal político" (1976, p. 107). Los escritores deben ensanchar las discusiones políticas y luchar porque estas sean cuestiones sociales, es decir, transformar el debate público de los intereses particulares en debate por la justicia colectiva (1976, p. 109). La sociedad en su conjunto debe implicarse en el progreso de un "movimiento simultáneo del organismo social” (1976, p. 54).
González Prada ve peligro y potencial en la población porque su escasa conciencia crítica la hace manipulable - como el hombre masa de Ortega y Gasset - pero puede llevar a cabo revoluciones evolutivas:

[...] las muchedumbres suelen ir hacia donde las empujan los listos y hacer el mal con la irresponsable ceguera del niño y del loco; pero saben también conducirse por ellas mismas, consumar las tremendas liquidaciones sociales y llevar hasta el sacrificio su adhesión a las ideas o a los hombres. (1933, p. 155)

De este modo, la población debe salir de su identidad de dominada para convertirse en un colectivo activo y crítico: "Si el Perú blasona de constituir nación, debe manifestar dónde se hallan los ciudadanos - los elementos esenciales de toda nacionalidad. Ciudadano quiere decir hombre libre; y aquí vegetan rebaños de siervos..." (1933, p. 159). La revolución pretendida por González Prada exige una nueva narración en la que se redefina la mismidad del sujeto como alguien con iniciativa y que, por lo tanto, también debe respetar la iniciativa de los otros, que constituyen la alteridad. En el modelo de Ricoeur, esto es esencial porque la forma con que un sujeto trata a los demás (alteridad) lleva al cambio de su identidad, pues modifica la otra faceta de su identidad, la ipseidad. Esto deberá ser estudiado en futuros trabajos, pero se apunta para señalar que el trabajo en la identidad no es necesariamente limitado a la individualidad, sino que está al servicio tanto de los sujetos como de los colectivos.

González Prada defiende la anarquía por su falta de confianza en la clase política del momento. Señala Ward que su falta de apoyo a la política convencional proviene en gran medida de su convicción de que las autoridades y leyes velaban únicamente por los intereses de unos pocos, en contra del conjunto de la población (2001, p. 144 y ss.). En su experiencia “[a]utoridad implica abuso, obediencia denuncia abyección, que el hombre verdaderamente emancipado no ambiciona el dominio sobre sus iguales ni acepta más autoridad que la de uno mismo sobre uno mismo" (González Prada, 1940, p. 17). Por este motivo, la política tradicional se asocia a la mentalidad dual de dominadores-dominados anclada en el pasado. Observa una fuerte tendencia por la que el poder corrompe las virtudes humanas: 
[...] bajo la acción de la política los caracteres más elevados se empequeñecen y las inteligencias más selectas se vulgarizan acabando por conceder suma importancia a las nimias cuestiones de forma y posponer los intereses humanos a las conveniencias de partido. (¡Cuántos hombres se anularon y hasta se envilecieron al respirar la atmósfera de un parlamento, ese sancta sanctorum de los políticos!) (González Prada, 1940, p. 35)

Nuestro autor no invita a una revolución anarquista sindical, sino a una revolución anarquista intelectual (Pereyra, 2009). Esta persigue acabar con tal mentalidad de dominio y conservación de los propios intereses personales para llevar al país a la libertad y a la apertura a nuevas ideas: "Los revolucionarios saludan hoy el mañana, el futuro advenimiento de una era en que se realice la liberación de todos los oprimidos y la fraternidad de todas las razas" (González Prada, 1940, p. 20). Es necesario un cambio radical de mentalidad: "Hay que sanearse y educarse a sí mismo, para quedar libre de dos plagas igualmente abominables: la costumbre de obedecer y el deseo de mandar" (1940, p. 22). Su proyecto político busca una revolución que permita llegar a motivaciones más allá de la satisfacción del estómago y poner como meta el progreso social:

[...] la Anarquía persigue el mejoramiento de la clase proletaria en el orden físico, intelectual y moral; concede suma importancia a la organización armónica de la propiedad; mas no mira en la evolución de la Historia una serie de luchas económicas. No, el hombre no se resume en el vientre, no ha vivido guerreando eternamente para comer y sólo para comer. (González Prada, 1940, p. 31)

Sin embargo, como percibe que la corrupción de los líderes imposibilita todo cambio, en ocasiones apela a la violencia:

[...] será la avenida torrentosa que todo lo arrasa convirtiendo en pedregal la buena tierra de labor, sino la inundación que ahoga las sabandijas y depone el limo fecundante en el suelo empobrecido. Será también la aurora del gran día. No faltará sangre. Las auroras tienen matices rojos. (1933, p. 156)
Una verdadera revolución necesita líderes con verdaderos ideales de bien común y progreso, por lo que "no hay buenas o malas formas de gobierno, sino buenos o malos gobernantes" (González Prada, 1940, p. 37). Debe ser dirigida por "faros, antorchas o postes" que muestren el camino, pero que dejen libertad a la población; y no por "pastores o guías" que controlen y vuelvan pasivos a los ciudadanos (González Prada, 1940, p. 29). Debe ser una revolución concebida no desde la satisfacción de las necesidades, sino desde las ideas y con una verdadera valentía para pelear por el bien común:

Para que la ley nacional sufriera una excepción, se necesitaría ver en el mando supremo a un hombre capaz de subyugar las muchedumbres e imponerse no sólo con la elevación de la inteligencia, sino con la generosidad de los sentimientos. (1933, pp. 184-185; cursivas en el original)

Este líder puede destacar tanto por la fuerza de sus acciones como de sus pensamientos:

[...] hay dos revoluciones: una en el terreno de las ideas, otra en el campo de los hechos. Ninguna prima sobre la otra, que la palabra suele llegar donde no alcanza el rifle, y un libro consigue arrasar fortalezas no derrumbadas por el cañón. (González Prada, 1940, p. 24)

En realidad, esas dos revoluciones deberían confluir en cuanto que el pensamiento y la acción se necesitan mutuamente para el progreso social: ambos pretenden una lógica cultural del bien común (González Prada, 1976, p. 340). Y, para ello, es necesario que se dé prioridad a la ciencia que permita el progreso de la sociedad y abra lugar a verdaderos pensadores. Una vez que ello exista, surgirán los buenos estilistas o escritores, aquellos que serán capaces de transmitir ideas e incitar a otros a elaborar las suyas propias (1976, pp. 102-103).

\section{Conclusiones}

A lo largo de este trabajo hemos visto que la buena revolución o revolución evolutiva se encuentra con muchos obstáculos. En primer lugar, estarían los líderes que llevan a cabo revoluciones sin ideales y que no 


\section{...esas dos revoluciones deberían confluir en cuanto que el pensamiento y la acción se necesitan mutuamente para el progreso social: ambos pretenden una lógica cultural del bien común (González Prada, 1976, p. 340).}

están dispuestos a sacrificarse por el pueblo, de modo que los dolores de estas recaen en la población: "los limeños dan en sus calles un terreno a las luchas, entierran a los muertos y fraternizan con los vencedores" (González Prada, 1933, p. 169).

En segundo lugar, esos líderes tienden a mantener la identidad dual de dominadores-dominados, la cual hace que la población no tenga ninguna iniciativa. La población vive pasiva y solo pendiente de qué hacen los que tienen el poder: "las provincias viven fascinadas por la capital, con los ojos fijos en ella, como aguardando las inspiraciones del oráculo infalible: no piensan ni actúan sin conocer el pensamiento ni recibir las órdenes de la Delfos peruana" (González Prada, 1933, p. 170). Incluso se produce la paradoja de que, a falta de juicio crítico, la población rechaza el verdadero progreso y toma a los oradores más vulgares por grandes pensadores: "Los buenos provincianos, a causa de una aberración óptica, ven desde lejos muy grande lo muy chico, tomando por Girardin al foliculario sin gramática ni sentido común, por Talleyrand al mulatillo de labia y tupé" (González Prada, 1933, p. 170).

En tercer lugar, se ha extendido una lógica cultural en la que la corrupción y la falta de solidaridad llevan al materialismo de las relaciones sociales:

\begin{abstract}
Mas nada debe sorprendernos en un país donde la corrupción corre a chorro continuo, donde se vive en verdadera bancarrota moral, donde los hombres se han convertido no sólo en mercenarios sino en mercaderías sujetas a las fluctuaciones de la oferta y la demanda. (González Prada, 1933, p. 167)
\end{abstract}

Pese a todo, cabe la esperanza. Otros países tuvieron largos períodos de inactividad, pero fueron capaces de abrirse al progreso. Hay países que " $[\mathrm{t}]$ ienen letargos de marmota y despertares de león. El Japón y la China sorprendieron a los teorizantes de las evoluciones lentas y apacibles" (1933, p. 155). Incluso, González Prada entiende que la inestabilidad de los países hispanoamericanos hace que estos estén abiertos a la revolución de manera que, si se produjera un cambio en las ideas que mueven a esta, podrían dar una sociedad verdaderamente avanzada:
Si hay un terreno llamado a recibir las ideas li- bertarias, es indudablemente la América del Sur y de un modo singular el Perú; aquí no existen las arraigadas tradiciones que en las viejas socieda- des oponen tanta resistencia a la germinación de todo lo nuevo; aquí la manía de pronunciamientos que agitó a nuestros padres y abuelos se ha tro- cado en espíritu de rebeldía contra todo poder y toda autoridad. (González Prada, 1940, pp. 45- 46; cursivas en el original).

\section{Notas}

1 Behanzin, rey de Dahomey (1889-1894), fue derrotado por Francia y se exilió en La Martinica, donde González Prada lo conoció. Aparece en sus escritos como paradigma del despotismo (Tauzin-Castellanos, 2004, p. 46).

2 Suluque se refiere al militar que acabó siendo conocido como Faustino l, quien gobernó Haití entre 1849 y 1859 . Este fue escogido presidente porque quienes lo propusieron pensaron que, como no sabía ni leer ni escribir, sería fácil de manipular. Sin embargo, demostró una gran iniciativa que le llevó a ser emperador y a numerosas campañas frustradas contra República Dominicana.

3 Para profundizar en la postura de González Prada frente a las medidas políticas que se tomaron en Perú tras la guerra, se recomienda la lectura del trabajo de Hugo Pereyra (2009). 


\section{Referencias bibliográficas}

Acosta, Y. (2017). Matar al padre. Barcelona: Alrevés.

Albizúrez Gil, M. (2016). Modernidades extremas. Textos y prácticas literarias en América Latina. Francisco Bilbao, Manuel González Prada, Manuel Ugarte y Manoel Bomfim. Madrid: Iberoamericana.

Bretoneche Gutiérrez, L. A. (2008). La concepción del hombre en el pensamiento de Manuel González Prada. (Tesis doctoral). Universidad Nacional Mayor de San Marcos, Lima, Perú.

García Márquez, G. (2004). Por la libre. Obra periodística (1974-1995). Barcelona: RBA.

González Prada, M. (1933). Bajo el oprobio. París: Tipografía de Louis Bellenand.

González Prada, M. (1940). Anarquía. Santiago de Chile: Ercilla S. A.

González Prada, M. (1976). Páginas libres. Horas de lucha. Venezuela: Biblioteca Ayacucho.

Larson, B. (2004). Trials of Nation Making. Liberalism, Race and Ethnicity in the Andes, 1810-1910. Cambridge: Cambridge University Press.

Martínez Riaza, A. (1994). El Perú y España durante el oncenio. El hispanismo en el discurso oficial y en las manifestaciones simbólicas. Histórica, 18 (2), 335-363.

Martínez Riaza, A. (2015). El peso de la ley: la política hacia los españoles en la independencia del Perú (1820-1826). Procesos: revista ecuatoriana de historia, 42, 65-97. https://doi.org/10.29078/rp.v1i42.569

Ortega, J. (1988). Crítica de la identidad: la pregunta por el Perú en su literatura. Ciudad de México: Fondo de Cultura Económica.

Pereyra Plasencia, H. (2009). Manuel González Prada y el radicalismo peruano. Lima: Academia Diplomática del Perú.

Ricoeur, P. (1996). Sí mismo como otro. Madrid: Siglo Veintiuno Editores.

Roca Sierra, M. (2003). La construcción del sujeto en la narrativa española actual. Madrid: Fundación Universitaria Española.

Sevilla-Vallejo, S. (2019). La lectura viva. Criterios psicológicos y didácticos y para fomentar el descubrimiento en los textos. En M. I. de Vicente-Yagüe y E. Jiménez Pérez (Eds.), Investigación e innovación en educación literaria (pp. 241-250). Madrid: Síntesis.

Sevilla-Vallejo, S. (2020). La construcción de la identidad personal y nacional en los Comentarios reales del Inca Garcilaso de la Vega. En S. Fernández Moreno, P. Mármol Ávila y Y. Pereira Melo (Coords.), Aproximaciones al nacionalismo en las literaturas hispánicas (pp. 207-238). Madrid: Universidad Autónoma de Madrid.

Tauzin-Castellanos, I. (1998). La vida literaria limeña y el papel de Manuel González Prada. En Universidad de Lima (Ed.). I Encuentro Internacional de Peruanistas. Estado de los estudios histórico-sociales sobre el Perú a fines del siglo XX (pp. 513-526). Lima: Universidad de Lima, Fondo de Cultura Económica, Unesco.

Tauzin-Castellanos, I. (2004). Escrituras y poderes: Manuel González Prada y el poder político (1912-1918). Escritura y Pensamiento, 7 (15), 37-63.

Tauzin-Castellanos, I. (2005). Manuel González Prada, acteur de la vie politique à l'aube du XXe siècle. Actes du 1er Congrès du GIS Amérique latine: Discours et pratiques de pouvoir en Amérique latine, de la période précolombienne à nos jours. Université de La Rochelle, 1-12.

https://halshs.archives-ouvertes.fr/halshs-00005640/document

Tavits, M. (2005). Causes of Corruption: Testing Competing Hypotheses. Oxford: Nuffield College, Oxford University. https://www.nuffield.ox.ac.uk/politics/papers/2005/Tavits\%20Nuffield\%20WP.pdf

Taylor, Ch. (1992). Sources of the Self: The Making of the Modern Identity. Cambridge: Harvard University Press.

Vázquez Montalbán, M. (2004). El hombre de mi vida. Barcelona: Planeta.

Velázquez Castro, M. (2005). Las máscaras de la representación. El sujeto esclavista y las rutas del racismo en el Perú (1775-1895). Lima: Universidad Nacional Mayor de San Marcos, Banco Central de Reserva del Perú.

Ward, Th. (2001). La Anarquía inmanentista de Manuel González Prada. Lima: Horizonte.

Ward, Th. (2003). González Prada, la mente y las manos. Revista peruana de filosofía aplicada, 11, 46-54.

Ward, Th. (2004). La resistencia cultural. La nación en el ensayo de las Américas. Lima: Editorial Universitaria. 